\title{
Enhancing the Mechanical Properties of Biodegradable Mg Alloys Processed by Warm HPT and Thermal Treatments
}

\author{
Andrea Mizelli-Ojdanic ${ }^{1,2}$, Jelena Horky ${ }^{3}$, Bernhard Mingler ${ }^{3}$, Mattia Fanetti ${ }^{4}$, Sandra Gardonio ${ }^{4}$, \\ Matjaz Valant $^{4}{ }^{(\mathbb{D}}$, Bartosz Sulkowski ${ }^{5}$, Erhard Schafler ${ }^{1} \mathbb{D}$, Dmytro Orlov ${ }^{4,6, * \mathbb{D}}$ and Michael J. Zehetbauer ${ }^{1}$
}

Citation: Mizelli-Ojdanic, A.; Horky, J.; Mingler, B.; Fanetti, M.; Gardonio,

S.; Valant, M.; Sulkowski, B.; Schafler,

E.; Orlov, D.; Zehetbauer, M.J.

Enhancing the Mechanical Properties of Biodegradable Mg Alloys

Processed by Warm HPT and Thermal Treatments. Materials 2021, 14, 6399. https://doi.org/10.3390/ ma14216399

Academic Editors: Frank Czerwinski and Alexei Vinogradov

Received: 4 September 2021

Accepted: 19 October 2021

Published: 25 October 2021

Publisher's Note: MDPI stays neutral with regard to jurisdictional claims in published maps and institutional affiliations.

Copyright: (c) 2021 by the authors. Licensee MDPI, Basel, Switzerland. This article is an open access article distributed under the terms and conditions of the Creative Commons Attribution (CC BY) license (https:// creativecommons.org/licenses/by/ $4.0 /)$.
1 Physics of Nanostructured Materials, Faculty of Physics, University of Vienna, 1090 Vienna, Austria; andrea.ojdanic@univie.ac.at (A.M.-O.); erhard.schafler@univie.ac.at (E.S.); michael.zehetbauer@univie.ac.at (M.J.Z.)

2 Faculty of Industrial Engineering, University of Applied Sciences-Technikum Wien, 1200 Vienna, Austria

3 Center for Health \& Bioresources, Biomedical Systems, AIT Austrian Institute of Technology GmbH, 2700 Wiener Neustadt, Austria; jelena.horky@ait.ac.at (J.H.); bernhard.mingler@ait.ac.at (B.M.)

4 Materials Research Laboratory, University of Nova Gorica, 5270 Ajdovscina, Slovenia; mattia.fanetti@ung.si (M.F.); sandra.gardonio@ung.si (S.G.); matjaz.valant@ung.si (M.V.)

5 Department of Material Science and Non-Ferrous Metals Engineering, Faculty of Non-Ferrous Metals, AGH-University of Science and Technology, 30-059 Kraków, Poland; sul5@agh.edu.pl

6 Division of Materials Engineering, Department Mechanical Engineering, LTH, Lund University, 22365 Lund, Sweden

* Correspondence: dmytro.orlov@material.lth.se; Tel.: +46-46-222-90-95

Abstract: In this study, several biodegradable Mg alloys (Mg5Zn, Mg5Zn0.3Ca, Mg5Zn0.15Ca, and

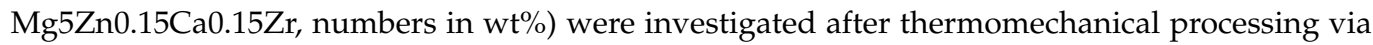
high-pressure torsion (HPT) at elevated temperature as well as after additional heat treatments. Indirect and direct analyses of microstructure revealed that the significant strength increases arise not only from dislocations and precipitates but also from vacancy agglomerates. By contrast with former low-temperature processing routes applied by the authors, a significant ductility was obtained because of temperature-induced dynamic recovery. The low initial values of Young's modulus were not significantly affected by warm HPT-processing. nor by heat treatments afterwards. Also, corrosion resistance did not change or even increase during those treatments. Altogether, the study reveals a viable processing route for the optimization of $\mathrm{Mg}$ alloys to provide enhanced mechanical properties while leaving the corrosion properties unaffected, suggesting it for the use as biodegradable implant material.

Keywords: severe plastic deformation (SPD); precipitates; vacancy agglomerates; magnesium alloys; biodegradability

\section{Introduction}

Biomaterials, i.e., titanium alloys or stainless steel, are commonly used as orthopedic implants in the form of screws, needles or plates. However, subsequent surgery is needed in many cases to remove the implant after the bone tissue is healed causing additional pain to the patient [1]. Also, these implants can cause problems in the human body due to their high Young's moduli compared to that of human bone, causing stress shielding [2]. Magnesiumbased biodegradable and biocompatible alloys have been becoming increasingly important as temporary implant materials in orthopedic applications [3,4]. One of the advantages of using Mg as orthopedic implants is the low Young's modulus, which approaches that of human bone. Besides being biocompatible, $\mathrm{Mg}$ is also biodegradable making it a good candidate for orthopedic implants that are absorbed by the human body after fulfilling their purpose, thus avoiding a second removal surgery [4,5]. The major drawback of using $\mathrm{Mg}$ is its low strength for providing stability to a damaged bone as well as its high corrosion 
rate in physiological environment, which may affect the mechanical properties as well as harm the tissue due to hydrogen evolution [6,7].

Alloying as well as applying severe plastic deformation leads to an optimization of $\mathrm{Mg}[8,9]$ with respect to mechanical and corrosion properties. Typical alloying elements are $\mathrm{Ca}, \mathrm{Zn}$ and $\mathrm{Zr}$; essential elements in the human body. $\mathrm{Ca}$ as well as $\mathrm{Mg}$ are both crucial for human bone's formation $[6,10]$. Zn has a positive impact on bone healing and cell reactions [11]. Although $\mathrm{Zr}$ does not play a biological role, the human body contains about $250 \mathrm{mg}$ of it, which makes the element biocompatible [12]. Mg alloys with $\mathrm{Ca}, \mathrm{Zn}$ or $\mathrm{Zr}$ have good biocompatibility and biodegradability, and also possess highly favorable mechanical properties $[13,14]$.

Besides alloying, mechanical properties can be further optimized by high-pressure torsion (HPT) and following heat treatment $[8,9,15]$. By means of dislocation and vacancy generation, HPT-processing [16] induces grain refinement and leads to a redistribution of solutes [17-20]. With additional heat treatments, the internal stresses are removed through re-distribution and loss of dislocations, this way decreasing the macroscopic strength; the generated vacancies, however, may form agglomerates which impede the dislocation movement and thus increase the macroscopic strength [8,21]. Moreover, nano-scale intermetallic precipitates form at special ageing conditions, as was shown by Orlov et al. for the ZK60 Mg alloy [22]. Also Mima and Tanaka [23] found three important low-temperature ranges for MgZn systems: (i) below $60{ }^{\circ} \mathrm{C}$ stable Guinier-Preston (GP) zones form; (ii) in a temperature range of $60-110^{\circ} \mathrm{C}$ stable rod-type and basal platelet-type precipitates form along with unstable GP zones; and (iii) above $110^{\circ} \mathrm{C}$ stable rod-type and basal platelet-type precipitates form, where the rod-type are the most stable ones [24,25].

As already reported, a proper processing method has been explored for the optimization of $\mathrm{Mg}$ alloys by Horky et al. [8] and Ojdanic et al. [9,15] with the compositions (in wt\%) Mg0.2Zn0.5Ca and Mg0.6Zn0.5Ca [8], and Mg5Zn0.3Ca, Mg5Zn0.15Ca, Mg5Zn0.15ca0.15Zr, and Mg5Zn [9,15]. Having processed all these materials by a special processing route, i.e., annealing at $350-400{ }^{\circ} \mathrm{C}$, subsequent furnace cooling to room temperature (RT) through 12-24 h, then followed by HPT-processing by 0.5 rotation at RT, and additional heat treatment at $100{ }^{\circ} \mathrm{C}$ for $24 \mathrm{~h}$, show samples with a very high strength increase of up to $250 \%$, but with a high brittleness.

Therefore, in the current study, the processing method for the named alloys was to optimize them in order to achieve better results regarding the combination of strength, ductility and corrosion. The thermal processing was changed to thermomechanical processing, by means of HPT-processing to high strains at elevated temperature and subsequent heat treatments. Except for hardness, tensile strength and Young's modulus, also ductility and corrosion properties in simulated body fluid (SBF) have been in focus of this work. The microstructure was analyzed in detail by electron microscopy, differential scanning calorimetry and X-ray line profile analysis [26,27].

\section{Experimental Procedure}

\subsection{Materials and Sample Preparation}

Four Mg alloys were studied with compositions Mg5Zn, Mg5Zn0.3Ca, Mg5Zn0.15Ca, and Mg5Zn0.15Ca0.15Zr. The alloys were cast at the LKR Leichtmetallkompetenzzentrum Ranshofen, a subsidiary of AIT Austrian Institute of Technology. The chemical composition of the alloys is shown in Table 1.

Table 1. Chemical composition of the investigated alloys.

\begin{tabular}{ccccc}
\hline Alloy & Mg [wt \%] & Zn [wt \%] & Ca [wt \%] & Zr [wt \%] \\
\hline Mg5Zn0.3Ca & $94.28 \pm 0.03$ & $5.44 \pm 0.03$ & $0.28 \pm 0.03$ & $/$ \\
Mg5Zn & $94.77 \pm 0.03$ & $5.23 \pm 0.03$ & $/$ & $/$ \\
Mg5Zn0.15Ca & $94.9 \pm 0.03$ & $5.1 \pm 0.03$ & $0.15 \pm 0.03$ & $/$ \\
Mg5Zn0.15Ca0.15Zr & $94.4 \pm 0.03$ & $5.6 \pm 0.03$ & $0.18 \pm 0.03$ & $0.18 \pm 0.03$ \\
\hline
\end{tabular}




\subsection{High-Pressure Torsion (HPT)-Processing}

Disc-shaped samples with a diameter of $10 \mathrm{~mm}$ and thickness of $0.7 \mathrm{~mm}$ were machined, for the sake of HPT-processing. HPT was achieved by applying a hydrostatic pressure of $4 \mathrm{GPa}$, and a rotation speed of $0.3 \mathrm{rot} / \mathrm{min}$. The samples have been deformed to shear strains:

$$
\gamma_{T}=\frac{2 \pi N r}{h}
$$

which becomes smaller by a factor $1 / \sqrt{ } 3$ when converted to a corresponding von-Mises strain $\varepsilon_{\mathrm{vM}}$ [16]. Here, $N$ means the number of rotations, $r$ the samples' radius, and $h$ the sample thickness. HPT- processing was carried out at $285^{\circ} \mathrm{C}$ and 10 rotations (i.e., $\varepsilon_{\mathrm{VM}}=330$ ) in order to produce a supersaturated solid-solution condition (SSSS) - a condition completely free from primary precipitates in casting.

\subsection{Heat Treatments}

Heat treatments of the HPT-processed samples were executed for different time periods up to $48 \mathrm{~h}$, and at different temperatures between $60^{\circ} \mathrm{C}$ and $150{ }^{\circ} \mathrm{C}$ in a silicon oil bath with a temperature variation under $\pm 0.5^{\circ} \mathrm{C}$. Then the samples were quenched in water having room temperature (RT) to ensure fast cooling and accurate heating periods [9].

\subsection{Characterization of Microstructure and Properties}

\subsubsection{Mechanical Properties}

For reliable tests of microhardness, the samples were polished by 1200 -grit SiC paper and cleaned with ethanol, in order to minimize oxidation and to obtain a defined surface condition.

Vickers hardness (HV0.05) was measured with an ANTON PAAR MHT-4 microhardness tester, by applying a load of $0.5 \mathrm{~N}$ for $10 \mathrm{~s}$. The indentation area was analyzed within a Light Microscope ZEISS 20 AXIOPLAN, by measuring the indents' diagonal lengths on images obtained from a CCD camera. Their average was not affected by any asymmetry of indents, and crack formation was not observed at all. For determination of the microhardness of an HPT-processed sample, the indents were distributed over the whole cross section, by applying them along full radii of the disc-shaped samples. Only indents with the same radius, i.e., distance from the center of the HPT disc, were averaged. At least 10 indents per sample state were evaluated.

The Young's modulus was measured by a microindentation tester ANTON PAAR MHT. At least 20 indents per sample state were carried out.

Strength and ductility were investigated by tensile testing. Dogbone-shaped specimens with a cross-section of $0.6 \times 0.6 \mathrm{~mm}^{2}$ and a parallel gauge length of $3.5 \mathrm{~mm}$ on average (Figure 1) were cut by spark erosion from the HPT-processed/heat treated discs. The tensile samples were cut at a position of approximately $3 \mathrm{~mm}$ off the center of the HPTdiscs. The tensile tests were performed by a micro-tensile low-load machine MESSPHYSIK suitable for measurements of tensile properties of small-scaled samples. Forces of up to $120 \mathrm{~N}$ at a strain rate of approximately $1 \times 10^{-3} \mathrm{~s}^{-1}$ were applied. To obtain reliable values for the tensile properties, at least three samples with the same preparation history were tested and averaged. 


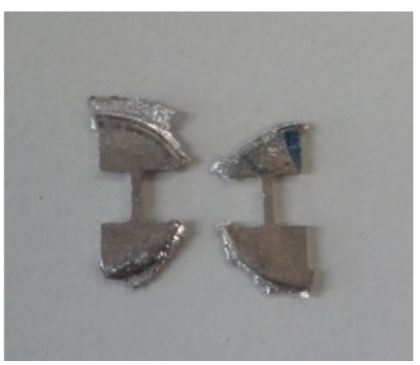

(a)

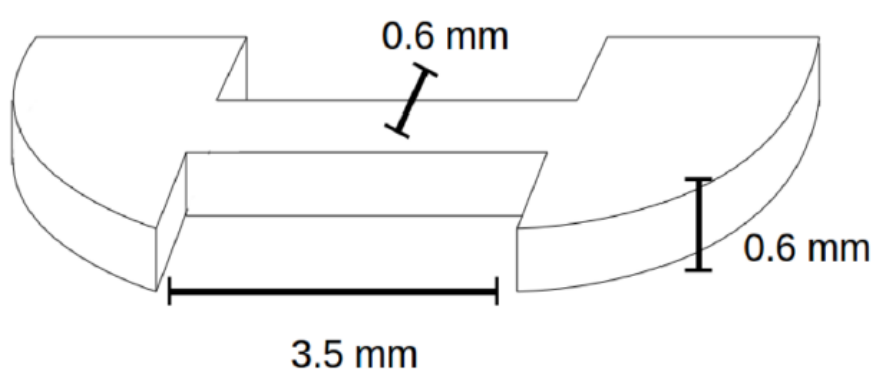

(b)

Figure 1. (a) Tensile test samples cut from Mg alloys in question, (b) dimensions of a cut sample [15].

\subsubsection{Electron Microscopy}

In order to investigate the grain structure and the distribution of precipitates at least at the microscale, scanning electron microscopy (SEM) in backscattered-electron (BSE) imaging mode was performed. For this purpose, a ZEISS SUPRA 55 VP SEM equipped with an energy-dispersive $X$-ray spectroscopy (EDX) analysis and imaging system was used. Samples were mechanically ground and polished by means of an ethanol lubricant and a $0.05 \mu \mathrm{m}$ alumina suspension. Evolutions of the microstructure on the nano-scale were investigated by transmission electron microscopy (TEM) and scanning transmission electron microscopy (STEM), using a JEOL JEM 2100F-UHR equipped with annular dark field detector. The specimens for TEM/STEM analyses were prepared as reported by Ojdanic et al. [15].

\subsubsection{Differential Scanning Calorimetry}

The measurements differential scanning calorimetry (DSC) were carried out with two instruments, a NETZSCH DSC204 and a PERKIN ELMER DSC8500. Heating was performed in a temperature range from 25 to $450{ }^{\circ} \mathrm{C}$ with a heating rate of $10 \mathrm{~K} / \mathrm{min}$. During DSC measurements, the occurrence of exothermic peaks indicates the annealing of deformation-induced defects while endotherm ones represent phase transformations. All the DSC peaks were identified by comparison with a base line obtained in a second DSC run with the same sample. The area of each peak represents the formation enthalpy of the annealing defect, from which its density can be evaluated. For dislocations-in a first-order approach-the stored energy $E_{\text {disl }}$ of a dislocation corresponds to its self energy i.e., mainly to its strain field [28]. The inner cut-off radius is approximately equal to the Burgers vector ( $b=0.32 \mathrm{~nm}$ ), the outer cut-off radius can be taken as the distance to the neighbouring dislocation, especially when-like in the current case of HPT deformation-the dislocations are part of cell/subgrain boundaries with screened strain fields [28]. $E_{\text {disl }}$ is then related to the dislocation density $\rho$ as:

$$
E_{d i s l}=G b^{2} \frac{\rho}{4 \pi \kappa} \times \ln \left((b \sqrt{\rho})^{-1}\right)
$$

Here, $G$ is the shear modulus $(G=17 \mathrm{GPa}) . \kappa$ denotes the arithmetic average of 1 and $(1-v)$, with $v=0.343$ as the Poisson ratio, assuming equal parts of edge and screw dislocations. This first-order approach neglects not only the core energy but also any interaction energy; thus it represents a lower limit of dislocation stored energy, and an upper limit of dislocation density.

By a similar first-order approach, the vacancy concentration $c_{v}$ can be evaluated from the stored energy of vacancies $E_{v a c}$ and the formation enthalpy per vacancy $\Delta H$, by means of Equation (3) (for $\mathrm{Mg}, \Delta H=1.27 \times 10^{-19} \mathrm{~J}=0.79 \mathrm{eV}$ [29]):

$$
c_{V}=\frac{E_{\text {vac }}}{\Delta H \times \chi \times N_{a}}
$$


with $\chi$ being the mole fraction, and $N_{a}$ the Avogadro's number.

Information on the type of the defect can be gained from the peak temperature $T_{\max }$ and the activation (defects' migration) enthalpy $Q$. The latter can be determined by the method of Kissinger [30] by evaluating the shift of the peak temperature while varying the heating rate. By using,

$$
\ln \left(\frac{\phi}{T^{2}}\right)=-\frac{Q}{R} \frac{1}{T_{\max }}+\text { const }
$$

for different heating rates $\Phi$ and peak temperatures $T_{\max }$, the activation enthalpy $Q$ can be calculated; $R$ means the gas constant.

\subsubsection{X-ray Diffraction Peak Profile Analysis (XPA)}

For the determination of dislocation density $\rho$, selected $\mathrm{Mg}$ samples have been subjected to X-ray diffraction peak profile analysis (XPA). As the X-ray source, a RIGAKU MM9 X-ray rotating anode generator was used providing monochromatic $\mathrm{Co}_{0}-\mathrm{K}_{\alpha}$ radiation, corresponding to a wavelength $\lambda=1.79 \mathrm{~nm}$. The peak profiles were taken by a curved positioned sensitive detector of the type INEL CPS-590, spanning an angular range of $90^{\circ}$ between $40^{\circ}$ and $130^{\circ}$ For understanding Bragg diffraction peak broadening in terms of dislocation density and crystallite size, see $[26,27]$. For the evaluation of dislocation density, the open source software (C)MWP-fit [27] was used.

\subsubsection{Texture Analysis}

Texture investigations were carried out with a BRUKER D-8 DISCOVER X-ray diffractometer equipped with a GADDS (general area diffraction detection system) area detector. The area detector can cover up to $35^{\circ}$ of $2 \theta$ range at one fixed position. A copper anode was used for the radiation of X-rays at $40 \mathrm{kV}$ and $40 \mathrm{~mA}$, with a wavelength of $0.154 \mathrm{~nm}$ for $\mathrm{CuK} \alpha_{1}$. X-ray texture measurements were performed by the reflection method, which is based on four main reflections in $\mathrm{Mg}$ used for the orientation distribution function (ODF), which was calculated by the Arbitrary Defined Cells (ADC) method with LaboTex3.0 texture analysis software (for details see [15]).

\subsubsection{Corrosion Tests}

The corrosion rate of the Mg5Zn alloy was measured by immersing samples in simulated body fluid (SBF27 from [31] with Tris- $\mathrm{HCl}$ buffer) at a human body temperature of $37^{\circ} \mathrm{C}$ for a period of three weeks and collecting the evolving hydrogen gas. Always two discs of each tested condition were immersed into $250 \mathrm{~mL}$ of SBF. The initial $\mathrm{pH}$ value of the SBF was 7.35 and increased to values between 8.2 and 8.8 within a week, being higher in the case of samples with a higher corrosion rate. After each week, the SBF was replaced to restore the initial $\mathrm{pH}$ value and ion concentration. Two experiments were performed for each tested condition to obtain a mean value and a standard deviation. More details of the corrosion measurements can be found in [15].

\section{Results}

\subsection{Effects of Severe Plastic Deformation at Elevated Temperature}

From EBSD and BSE investigations done in all materials studied in this work, the grain size of the as-cast samples has been evaluated to be $49 \pm 5 \mu \mathrm{m}$ in average (Figure 2), after HPT-deformation at $285^{\circ} \mathrm{C}$ as between $10-40 \mu \mathrm{m}$, i.e., $25 \pm 3 \mu \mathrm{m}$ on average (Figure 3a). That means that in spite of the severe plastic deformation processing, the grain size remained close to that of the as-cast materials i.e., within about a factor of 2 . As concerns the precipitates, SEM images of the as-cast alloys show a huge number of primary ones with a size of 5-10 $\mu \mathrm{m}$ that are distributed homogeneously in each of the sample conditions (Figure 2). The total volume fraction of primary precipitates was determined to be approximately $\sim 2 \%$, as estimated from the total area of the particles by means of standard image analysis methods. A detailed EDS analysis on primary precipitates can be found in [15]. 


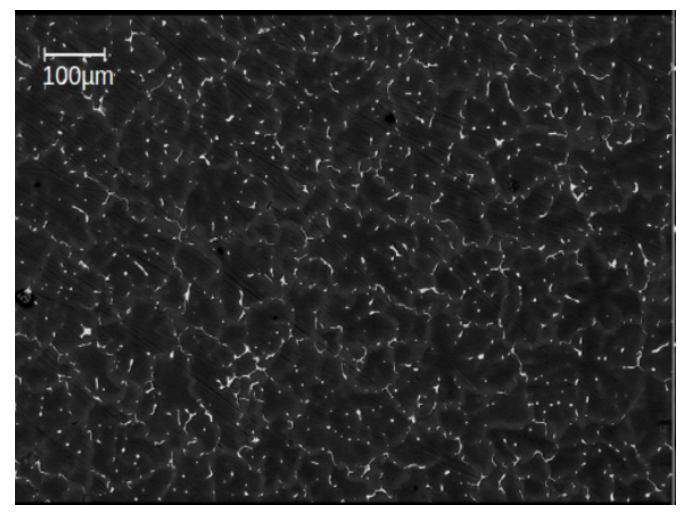

(a)

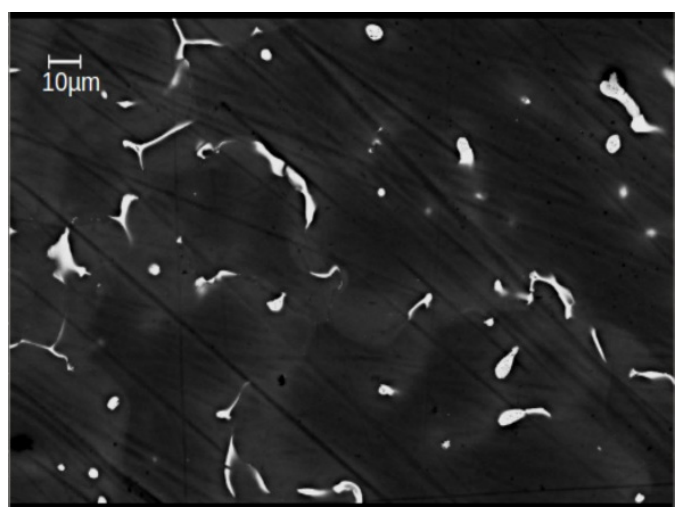

(b)

Figure 2. Scanning electron microscope (SEM) images of the as-cast alloy Mg5Zn0.3Ca, with low (a) and high (b) magnification [15].

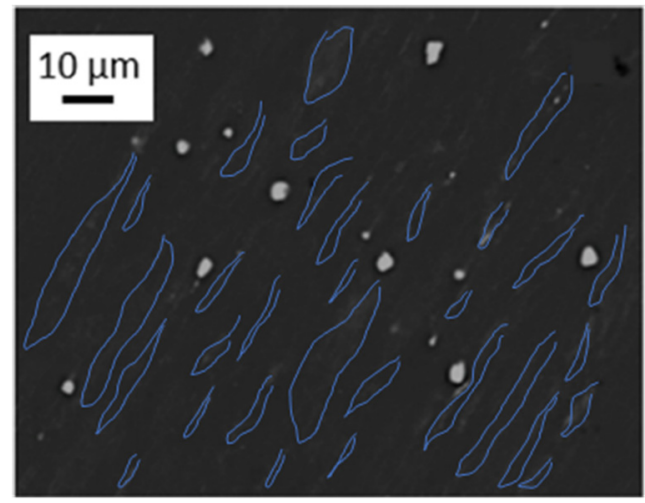

(a)

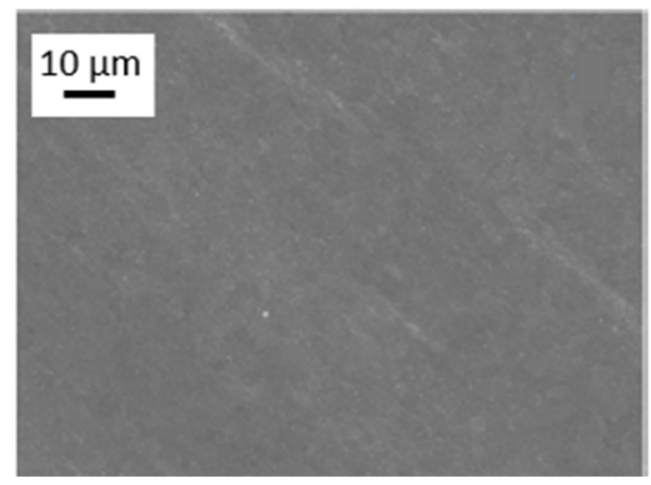

(c)

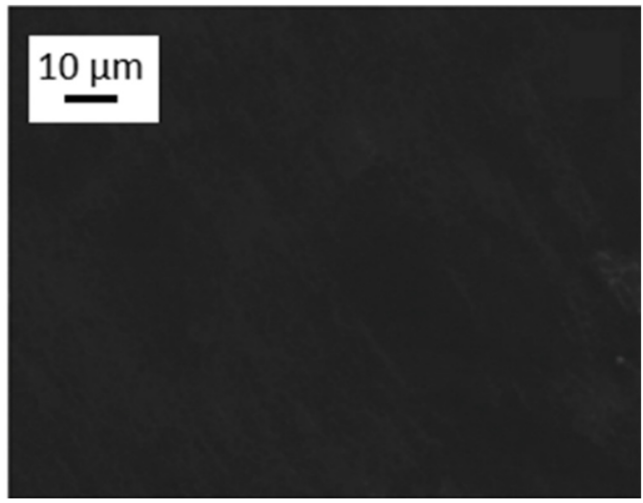

(b)

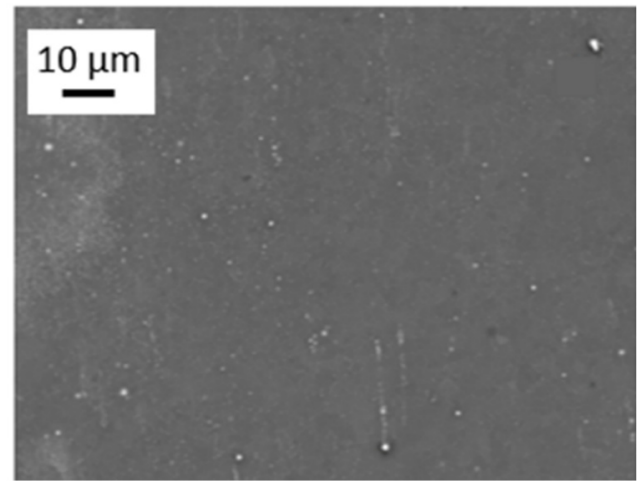

(d)

Figure 3. SEM images of high-temperature high-pressure torsion (HPT)-processed samples at $285^{\circ} \mathrm{C}, 4 \mathrm{GPa}$ and 10 rotations, taken from areas with $\gamma_{\mathrm{T}} \sim 320$, for the materials (a) Mg5Zn0.3Ca, (b) Mg5Zn, (c) Mg5Zn0.15Ca, and (d) Mg5Zn0.15Ca0.15Zr. In (a), the grain area contrasts have been visualized by blue lines.

HPT processing at $285^{\circ} \mathrm{C}$, the primary precipitates become thermally and mechanically re-solutionized. The SSSS-condition could be achieved for all investigated alloys (Figure 3), except for Mg5Zn0.3Ca, which still showed occasional residual primary precipitates (Figure 3a). Nevertheless, for all Mg alloys including the latter, the volume fraction of primary precipitates could be decreased to less than $1 \%$.

As in the first investigation, microhardness (HV0.05) measurements were taken. In Figure 4, the microhardness values are presented as a function of torsional shear strain 
$\gamma_{\mathrm{T}}$ calculated by means of Equation (1). The values increase with increasing $\gamma_{\mathrm{T}}$, and finally reach saturation at about HV0.05 $=100$ for all four alloys. Starting from the as-cast condition, the samples show an increase of microhardness by $35 \%$ for Mg5Zn0.15Ca, $25 \%$ for Mg5Zn0.15Ca0.15Zr, $55 \%$ for Mg5Zn0.3Ca, and $42 \%$ for Mg5Zn.

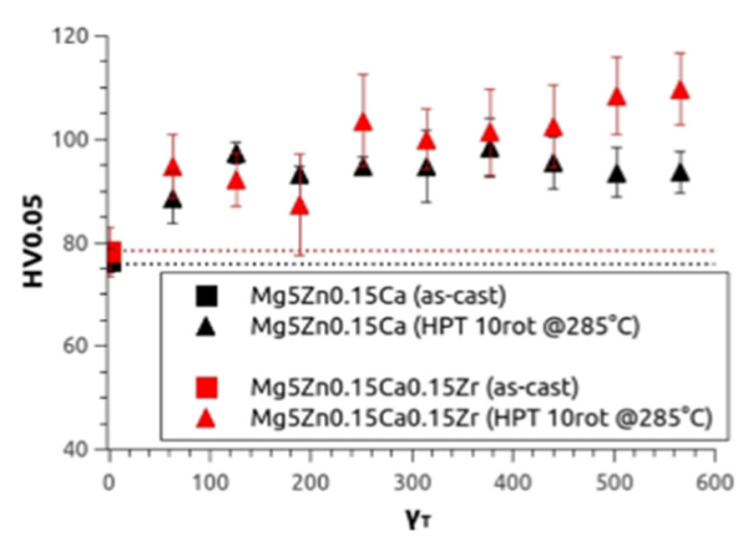

(a)

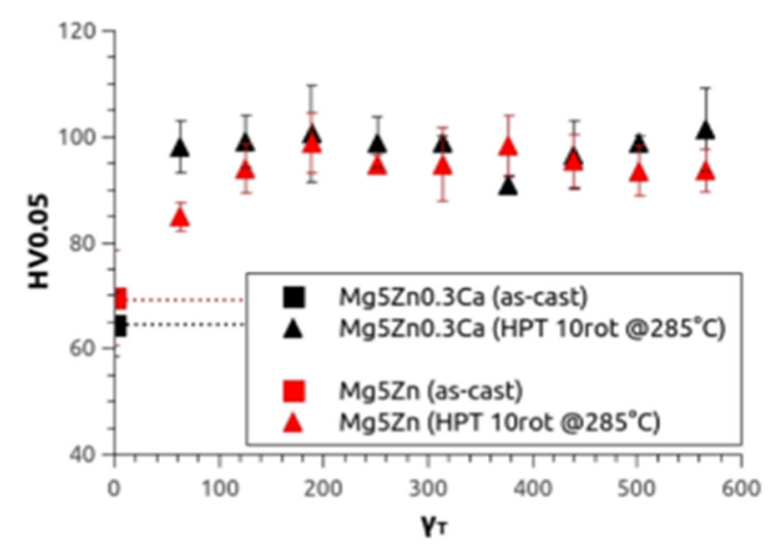

(b)

Figure 4. Microhardness results of (a) Mg5Zn0.15Ca (black) and Mg5Zn0.15Ca0.15Zr (red), (b) Mg5Zn0.3Ca (black) and $\mathrm{Mg} 5 \mathrm{Zn}$ (red) in the as-cast condition (dotted line) and after HPT deformation at $4 \mathrm{GPa}, 10$ rotations at $285^{\circ} \mathrm{C}$ as a function of the torsional strain.

\subsection{Effects of Isothermal Heat Treatments}

After HPT processed at elevated temperature, some samples were also heat-treated for up to $48 \mathrm{~h}$ at temperatures between $60-150{ }^{\circ} \mathrm{C}$. During the heat treatments, no changes in the grain size/size distribution were obtained which was present immediately after the warm HPT processing. Exemplarily for Mg5Zn0.3Ca, Figure 5 demonstrates the effects of various heat treatments on microhardness, showing a significant hardness peak at $100{ }^{\circ} \mathrm{C}$ after $1440 \mathrm{~min}(24 \mathrm{~h})$ of heat treatment and a similar high peak at $150{ }^{\circ} \mathrm{C}$ after $120 \mathrm{~min}(2 \mathrm{~h})$ of heat treatment. For all alloys, a hardness increase of around $25 \%$ could be observed at $100{ }^{\circ} \mathrm{C}$ and around $20 \%$ at $150{ }^{\circ} \mathrm{C}$ (Table 2).

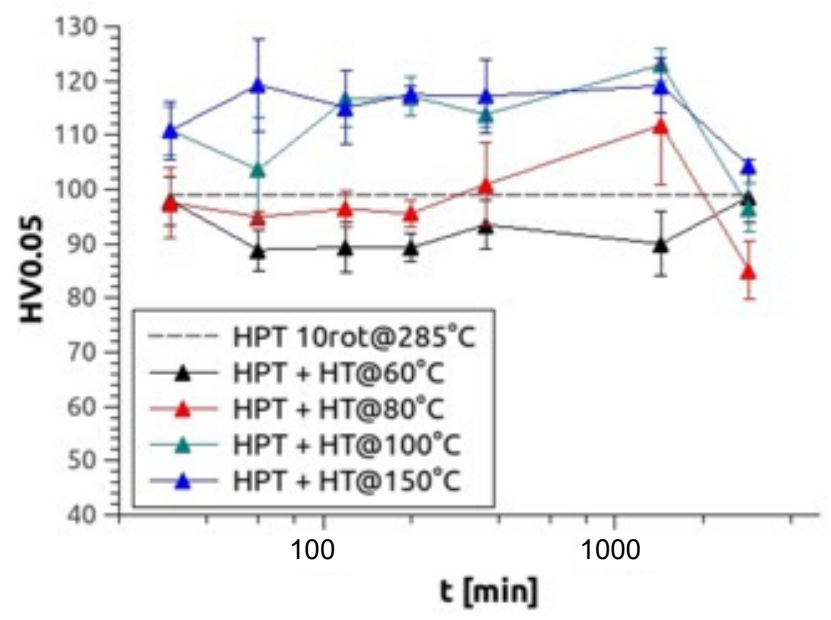

Figure 5. Microhardness results of Mg5Zn0.3Ca, HPT-processed at $4 \mathrm{GPa}$ and 10 rotations at $285^{\circ} \mathrm{C}$ and heat treated at $60{ }^{\circ} \mathrm{C}$ (black), $80^{\circ} \mathrm{C}$ (red), $100{ }^{\circ} \mathrm{C}$ (green) and $150{ }^{\circ} \mathrm{C}$ (blue) up to $48 \mathrm{~h}$. 
Table 2. Microhardness values of all investigated alloys in all conditions. HPT has been performed at $285^{\circ} \mathrm{C}$.

\begin{tabular}{ccc}
\hline Sample & Condition & HV0.05 \\
\hline Mg5Zn0.3Ca & as-cast & $65 \pm 6$ \\
& $\mathrm{HPT}$ & $99 \pm 3$ \\
& $\mathrm{HPT}+\mathrm{HT} 100{ }^{\circ} \mathrm{C}, 24 \mathrm{~h}$ & $123 \pm 6$ \\
$\mathrm{HPT}+\mathrm{HT} 150{ }^{\circ} \mathrm{C}, 2 \mathrm{~h}$ & $119 \pm 12$ \\
& as-cast & $70 \pm 9$ \\
& $\mathrm{HPT}$ & $95 \pm 3$ \\
$\mathrm{Mg} 5 \mathrm{Zn} 0.15 \mathrm{Ca} 0.15 \mathrm{Zr}$ & $\mathrm{HPT}+\mathrm{HT} 100{ }^{\circ} \mathrm{C}, 24 \mathrm{~h}$ & $114 \pm 10$ \\
& $\mathrm{HPT}+\mathrm{HT} 150{ }^{\circ} \mathrm{C}, 2 \mathrm{~h}$ & $106 \pm 6$ \\
& as-cast & $79 \pm 5$ \\
& $\mathrm{HPT}$ & $101 \pm 12$ \\
& $\mathrm{HPT}+\mathrm{HT} 100{ }^{\circ} \mathrm{C}, 24 \mathrm{~h}$ & $125 \pm 6$ \\
& $\mathrm{HPT}+\mathrm{HT} 150{ }^{\circ} \mathrm{C}, 2 \mathrm{~h}$ & $123 \pm 4$ \\
\hline
\end{tabular}

\subsection{Tensile Strength and Ductility}

Tensile tests on all four alloys were conducted on as-cast material, HPT deformed, and additionally heat treated for $24 \mathrm{~h}$ at $100{ }^{\circ} \mathrm{C}$. All tests were performed until failure, which occurred close to the center of specimens. Typical engineering stress-strain curves obtained by micro-tensile testing are presented in Figure 6. Table 3 presents values of the yield strength determined at $1 \%$ of plastic strain, as well as those of the ultimate tensile strength (UTS). The post-HPT heat treatment led to marked increases in yield strength of up to $20 \%$ for $\mathrm{Mg} 5 \mathrm{Zn} 0.15 \mathrm{Ca} 0.15 \mathrm{Zr}$, while $\mathrm{Mg} 5 \mathrm{Zn} 0.3 \mathrm{Ca}$ and $\mathrm{Mg} 5 \mathrm{Zn} 0.15 \mathrm{Ca}$ showed a slight decrease. The latter was shown also by the values of ultimate tensile strength for the same alloys. However, the values of elongation to failure which still reached up to $19 \%$ after HPT were not significantly affected by the thermal treatment after HPT-processing. The average values for strength and ductility obtained from tensile tests are summarized in Table 3.

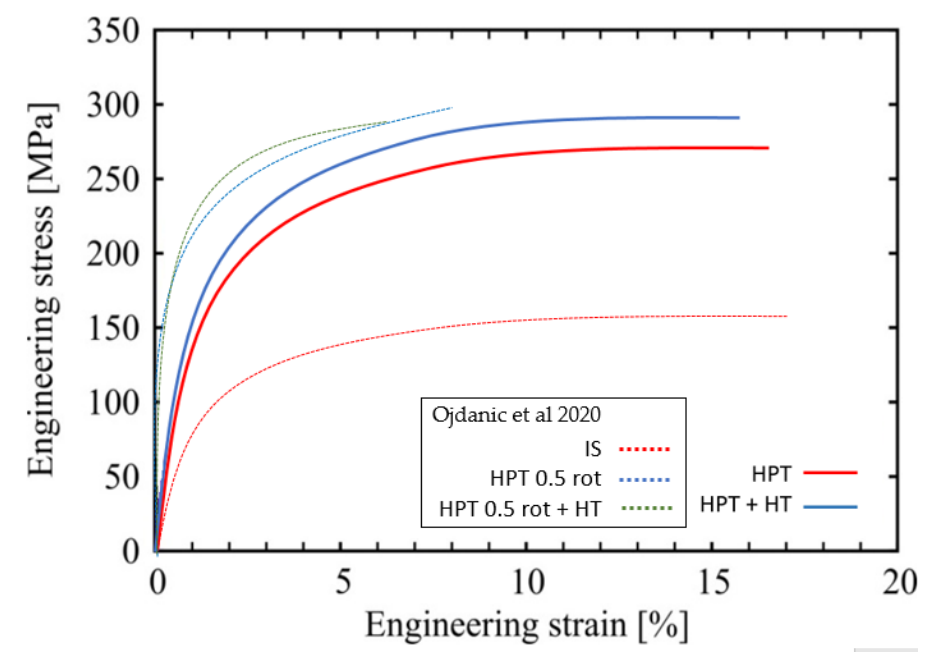

Figure 6. Representative tensile stress-strain curves for Mg5Zn0.15Ca, HPT-processed (10 rotations at $285^{\circ} \mathrm{C}$ ) (full line-red) and after additional heat treatment at $100{ }^{\circ} \mathrm{C}$ for $24 \mathrm{~h}$ (full-line blue). For comparison, the dotted lines show the results of the previous study [15] of the same alloy processed as follows: annealing at $450{ }^{\circ} \mathrm{C}$ for $24 \mathrm{~h}$ and then furnace cooled to RT (IS), HPT-processed at $4 \mathrm{GPa}$ and 0.5 rotations at RT (HPT 0.5 rot), and HPT plus heat treatment at $100{ }^{\circ} \mathrm{C}$ for $24 \mathrm{~h}$ (HPT 0.5 $\operatorname{rot}+\mathrm{HT})$. 
Table 3. Measured yield strength $\sigma_{\text {yield }}$ and ultimate tensile strength (UTS), as well as ductility (total elongation) $\varepsilon_{\text {total }}$ for all tested alloys in all conditions ('HPT' at $4 \mathrm{GPa}, 10$ rotations at $285^{\circ} \mathrm{C}$ and heat treatment ' $\mathrm{HT}$ ' at $100{ }^{\circ} \mathrm{C}$ for $24 \mathrm{~h}$ ).

\begin{tabular}{ccccc}
\hline Sample & Condition & $\boldsymbol{\sigma}_{\text {yield }}[\mathrm{MPa}]$ & UTS [MPa] & $\varepsilon_{\text {total }}[\%]$ \\
\hline Mg5Zn0.3Ca & $\mathrm{HPT}$ & $223 \pm 34$ & $248 \pm 37$ & $18 \pm 2$ \\
Mg5Zn0.3Ca & $\mathrm{HPT}+\mathrm{HT}$ & $220 \pm 33$ & $249 \pm 37$ & $17 \pm 2$ \\
Mg5Zn & $\mathrm{HPT}$ & $156 \pm 23$ & $215 \pm 32$ & $17 \pm 2$ \\
Mg5Zn & $\mathrm{HPT}+\mathrm{HT}$ & $170 \pm 26$ & $245 \pm 37$ & $19 \pm 2$ \\
Mg5Zn0.15Ca & $\mathrm{HPT}$ & $236 \pm 35$ & $270 \pm 41$ & $16 \pm 2$ \\
Mg5Zn0.15Ca & $\mathrm{HPT}+\mathrm{HT}$ & $226 \pm 34$ & $250 \pm 38$ & $19 \pm 2$ \\
Mg5Zn0.15Ca0.15Zr & $\mathrm{HPT}$ & $226 \pm 34$ & $283 \pm 42$ & $19 \pm 2$ \\
Mg5Zn0.15Ca0.15Zr & $\mathrm{HPT}+\mathrm{HT}$ & $270 \pm 41$ & $283 \pm 42$ & $16 \pm 2$ \\
\hline
\end{tabular}

\subsection{Evolution of Texture and Young's Modulus}

Pole figures (002) (010) (011) and (102) of the samples were determined, after HPTprocessing as well as after additional thermal treatment (Figure 7). While the textures after low-temperature HPT-processing found in our previous paper [15] are typical shear textures of $\mathrm{Mg}$ and Mg-rich alloys [32,33] the current textures not only comprise shear deformation components but also some features of dynamic recrystallization (after HPT, upper raw). As already observed with the low-temperature HPT-processed samples [15], thermal treatment at $100{ }^{\circ} \mathrm{C}$ leads to a randomization of the texture, as a consequence of static recrystallization. Such effects have been already observed by us [32] and other authors [33] pioneering the textures of severely deformed $\mathrm{Mg}$ and $\mathrm{Mg}$ alloys.

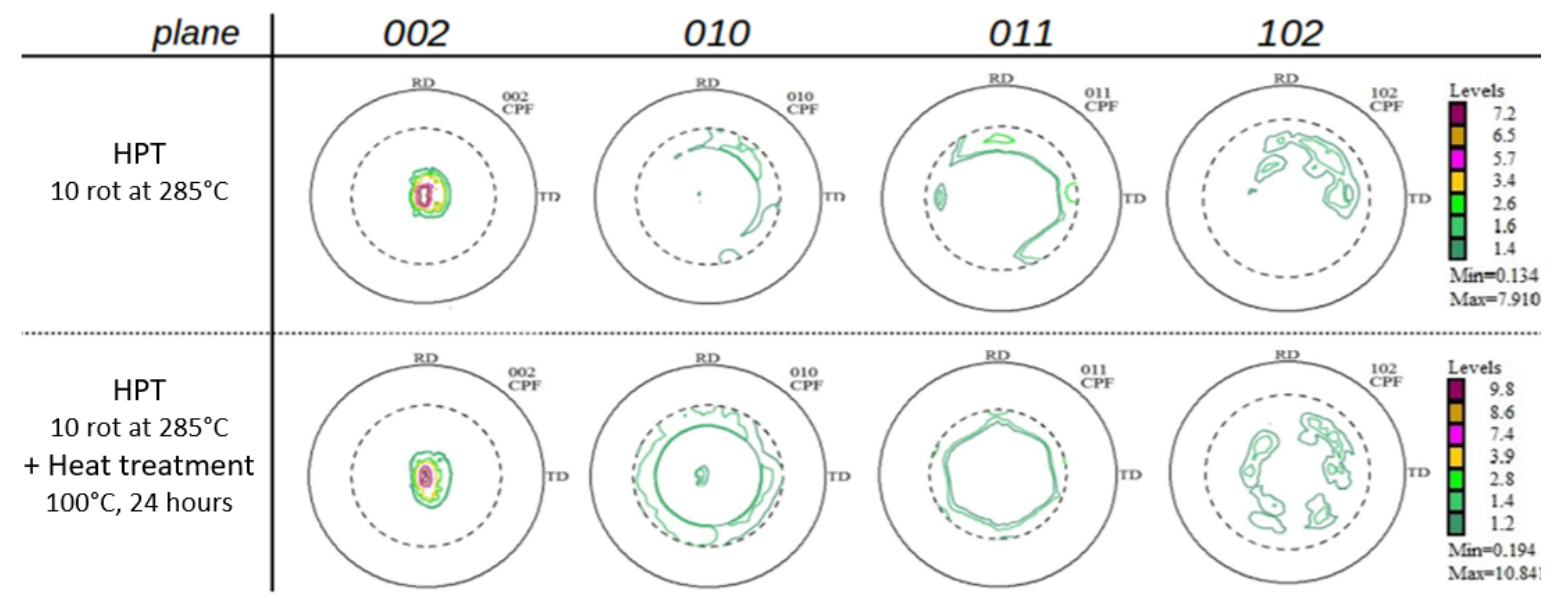

Figure 7. Pole figures displaying crystallographic textures of $\mathrm{Mg} 5 \mathrm{Zn} 0.15 \mathrm{Ca}$ after various treatments.

Values of Young's modulus E of all materials and treatments were evaluated from microhardness indentation tests. After HPT-processing, they all were between 31-42 GPa (Table 4) with errors of about $\pm 2 \mathrm{GPa}$. The thermal treatment at $100{ }^{\circ} \mathrm{C}$ did not change the Young's modulus significantly, i.e., were close to the measuring error. In order to substantiate these results, we tried to simulate the magnitude of Young's modulus and its changes due to the thermal treatment at $100^{\circ} \mathrm{C}$, at least for the materials Mg5Zn0.3Ca and $\mathrm{Mg} 5 \mathrm{Zn} 0.15 \mathrm{Ca}$. For these simulations, the procedures described in detail in paper [15] have been applied. Again, the changes due to thermal treatment were negligible. As in [15], the constant positive offset of the simulated values of $\mathrm{E}$ compared to the experimental ones may have arisen from the upper-limit approach of the calculation as well as from the neglect of constituents $\mathrm{Zn}$ and $\mathrm{Ca}$ therein. 
Table 4. Young's modulus E measured by indentation microhardness of the alloys after HPTprocessing by 10 rotations at $285^{\circ} \mathrm{C}$, and after additional heat treatment at $100{ }^{\circ} \mathrm{C}$ for $24 \mathrm{~h}$. Simulated values $\mathrm{E}_{\text {sim }}$ are given in parentheses.

\begin{tabular}{|c|c|c|}
\hline Sample & Condition & $\mathrm{E}\left(\mathrm{E}_{\text {sim }}\right)[\mathrm{GPa}]$ \\
\hline $\mathrm{Mg} 5 \mathrm{Zn} 0.3 \mathrm{Ca}$ & HPT & $38 \pm 2(45)$ \\
\hline Mg5Zn0.3Ca & $\mathrm{HPT}+\mathrm{HT}$ & $37 \pm 1(45)$ \\
\hline Mg5Zn & HPT & $34 \pm 1$ \\
\hline Mg5Zn & $\mathrm{HPT}+\mathrm{HT}$ & $34 \pm 2$ \\
\hline Mg5Zn0.15Ca & $\mathrm{HPT}$ & $35 \pm 1(58)$ \\
\hline Mg5Zn0.15Ca & $\mathrm{HPT}+\mathrm{HT}$ & $31 \pm 1(60)$ \\
\hline Mg5Zn0.15Ca0.15Zr & $\mathrm{HPT}$ & $38 \pm 2$ \\
\hline Mg5Zn0.15Ca0.15Zr & $\mathrm{HPT}+\mathrm{HT}$ & $42 \pm 1$ \\
\hline
\end{tabular}

\subsection{Electron Microscopy Analysis of Precipitates}

For TEM analyses the alloy Mg5Zn was investigated in the following conditions:

(1) HPT-processed at $4 \mathrm{GPa}$ for 10 rotations at $285^{\circ} \mathrm{C}$;

(2) HPT-processed at $4 \mathrm{GPa}$ for 10 rotations at $285^{\circ} \mathrm{C}$ and heat treated at $100{ }^{\circ} \mathrm{C}$ for $24 \mathrm{~h}$;

(3) HPT-processed at $4 \mathrm{GPa}$ for 10 rotations at $285^{\circ} \mathrm{C}$ and heat treated at $150{ }^{\circ} \mathrm{C}$ for $2 \mathrm{~h}$.

Although the primary precipitates were eliminated through the HPT processing, small prismatic precipitates could be found in all material states having lengths between 5-20 nm, thicknesses less than $1 \mathrm{~nm}$ and orientations along three $<\mathrm{a}>$ directions at $120^{\circ} / 60^{\circ}$ to each other. The prismatic platelets show homogeneous distributions in the as-HPT-processed as well as in additionally heat treated at $100{ }^{\circ} \mathrm{C}$ samples (conditions (1) and (2), Figure 8a-c). The sample heat treated at $150{ }^{\circ} \mathrm{C}$ (3) showed not only prismatic but also rod-like precipitates aligned in $<0001>$ directions, Figure $8 \mathrm{~d}-\mathrm{f}$. The rod-like precipitates have been formed far away from the prismatic precipitates, Figure 8e, also in much smaller densities.

\subsection{Determination of Severe Plastic Deformation (SPD)-Induced Defect Densities by Differential Scanning Calorimetry (DSC) and XPA}

Differential scanning calorimetry not only allows for measurement of phase transitions but also can detect lattice defects through selective annealing. Concerning SPD-processed materials, Setman et al. [18] identified-as a function of annealing temperature-three annealing peaks on HPT-processed $\mathrm{Ni}$ (99.998\% purity): (i) from the annealing of single and/or double vacancies, (ii) from vacancy agglomerates, and (iii) from dislocations. Because the temperature of the latter often depends on the deformation strain applied, the annealing peaks of the latter two defects can overlap. As a representative for the DSC scans of all Mg alloys investigated, Figure 9 shows a scan of an HPT-processed Mg5Zn0.3Ca sample. There appear two exotherm peaks that are called 'peak I' and 'peak II'. At about $400^{\circ} \mathrm{C}$, a sharp endotherm peak emerges which indicates the occurrence of a phase transformation, probably the dissolution of precipitates found by TEM as indicated in Section 3.5. Beyond this temperature, the microstructure of original as-cast material is reached so that the DSC mediated defect analysis was stopped.

The stored energies $\mathrm{E}_{\text {total }}$ of the HPT-induced defects given in Table 5 (peak I) and Table 6 (peak II) are evaluated from the areas of the peaks, after having averaged them from 4 independent experiments. The error given represents the maximum deviation. 


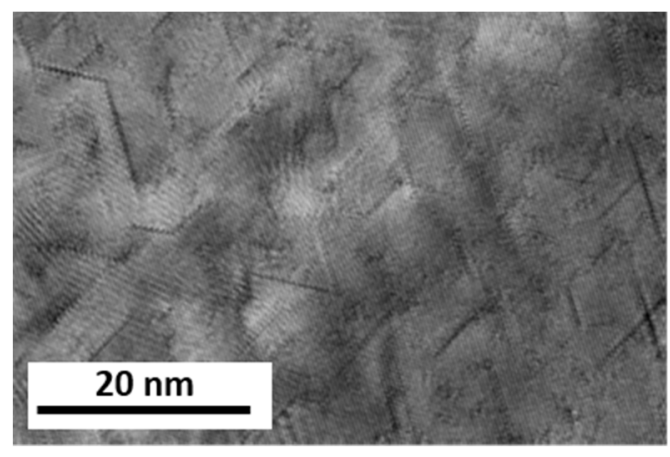

(a)

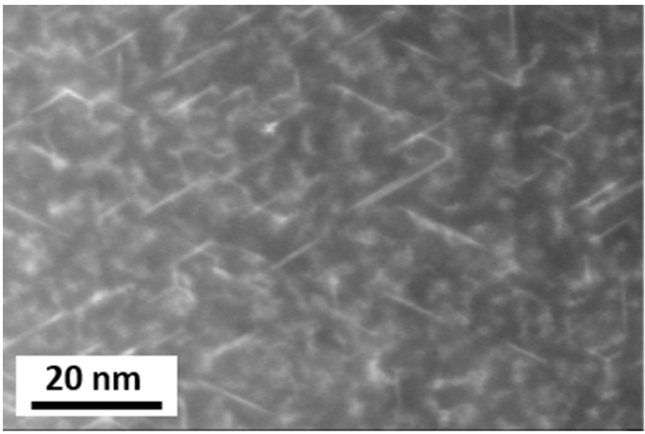

(c)

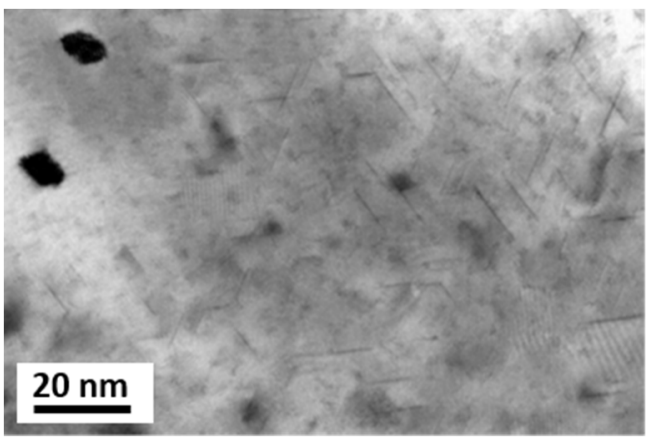

(e)

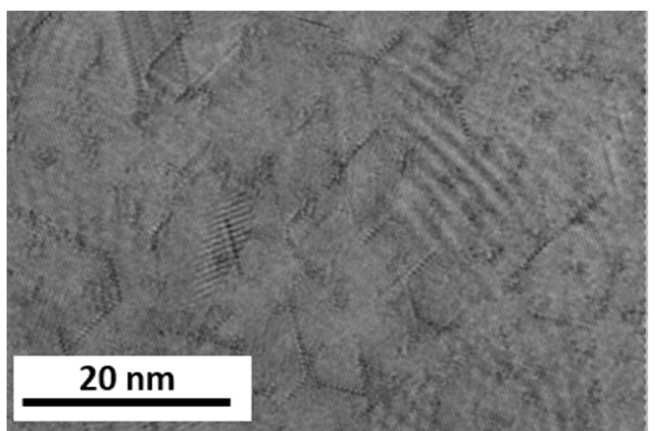

(b)

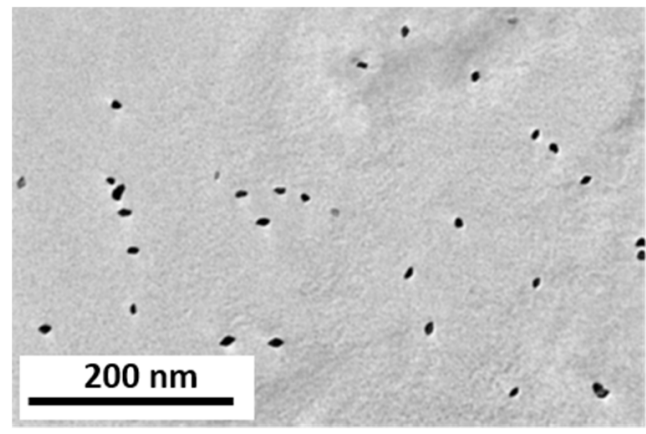

(d)

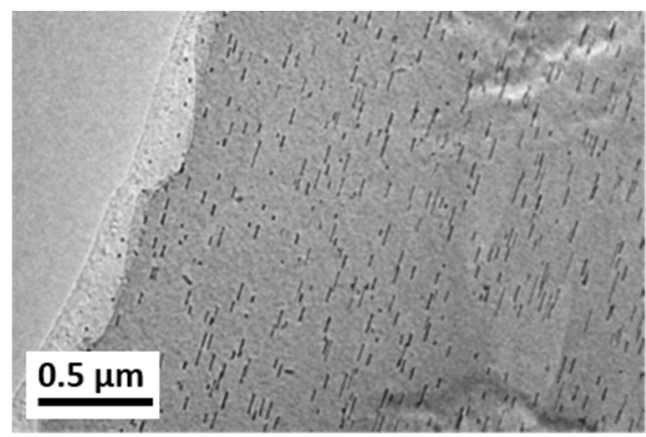

(f)

Figure 8. Micrographs revealing precipitate structures in Mg5Zn samples: (a) bright-field transmission electron microscopy (TEM) after HPT-processing; (b) bright-field TEM and (c) HAADF STEM after HPT and following heat treatment at $100{ }^{\circ} \mathrm{C}$ for $24 \mathrm{~h}$; (d-f) bright-field TEM after HPT and following heat treatment at $150{ }^{\circ} \mathrm{C}$ for $2 \mathrm{~h}$. In the micrographs (a-e), the observation is close to $<0001>$, while in (f) it is close to $<10 \overline{1} 0>$.

From the measured stored energies $\mathrm{E}_{\text {total }}$ of the defects, their concentrations can be determined by means of Equations (2) and (3). Because of the possible overlap of peaks, however, for the determination of the real densities of vacancies, it was the best way to follow a procedure already applied in [18] and in the previous paper [15] 15 of the authors. Here, from the measured dislocation density $\rho$, the stored energy of dislocations $E_{\text {disl }}$ was calculated via Equation (2) and subtracted from the total stored energy $E_{\text {total, }}$ with the stored energy left to be attributed to the vacancy-type defects, $E_{v a c}$, thus yielding, via Equation (3), the vacancy concentrations $c_{V}$. Those, together with the dislocation densities measured by XPA, are presented in Tables 5 and 6 for both peaks for all materials studied. 


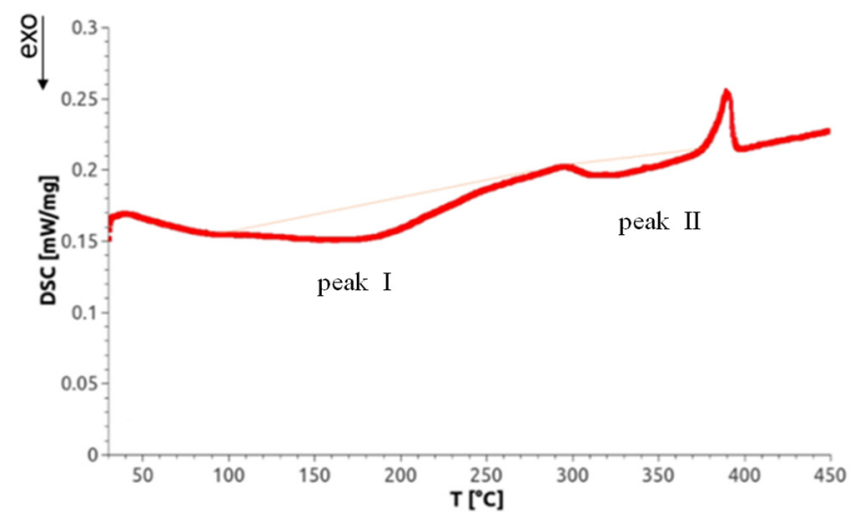

Figure 9. A representative heat flow curve as function of the temperature, for warm HPT-processed Mg5Zn0.3Ca exhibiting two exothermal peaks I and II. The thin red line is qualitatively similar to the base line which has been recorded in a second differential scanning calorimetry (DSC) run (for details see Section 2.4.3).

Table 5. Measured and calculated data for DSC peak I. $\rho$ is the dislocation density (measured), $E_{\text {disl }}$ is the dislocations' stored energy calculated from $\rho$, and $c_{V}$ is the vacancy concentration (calculated).

\begin{tabular}{cccccc}
\hline Sample & $\mathbf{E}_{\text {total }}[\mathbf{J} / \mathbf{g}]$ & $\boldsymbol{\rho}\left[\mathbf{1 0}^{\mathbf{1 4}} \mathbf{~ m}^{-\mathbf{2}}\right]$ & $\mathbf{E}_{\text {disl }}[\mathbf{J} / \mathbf{g}]$ & $\mathbf{E}_{\mathbf{v a c}}[\mathbf{J} / \mathbf{g}]$ & $\mathbf{c}_{\mathbf{v}}\left[\mathbf{1 0}^{-\mathbf{4}}\right]$ \\
\hline Mg5Zn & $2.4 \pm 0.5$ & $2.5 \pm 0.1$ & $0.01 \pm 0.001$ & $2.4 \pm 0.3$ & $7 \pm 1.0$ \\
Mg5Zn0.3Ca & $1.9 \pm 0.43$ & $3.0 \pm 0.1$ & $0.1 \pm 0.01$ & $1.8 \pm 0.4$ & $5 \pm 1.0$ \\
Mg5Zn0.15Ca & $2.7 \pm 0.13$ & $3.6 \pm 0.1$ & $0.04 \pm 0.01$ & $2.7 \pm 0.2$ & $8 \pm 0.6$ \\
Mg5Zn0.15Ca0.15Zr & $2.6 \pm 0.1$ & $2.5 \pm 0.1$ & $0.01 \pm 0.001$ & $2.6 \pm 0.04$ & $8 \pm 0.1$ \\
\hline
\end{tabular}

Table 6. Measured and calculated data for DSC peak II. $\rho$ is the dislocation density (measured), $E_{\text {disl }}$ is the dislocations' stored energy calculated from $\rho$, and $c_{V}$ is the vacancy concentration (calculated).

\begin{tabular}{cccccc}
\hline Sample & $\mathbf{E}_{\text {total }}[\mathbf{J} / \mathbf{g}]$ & $\boldsymbol{\rho}\left[\mathbf{1 0}^{\mathbf{1 4}} \mathbf{~ m}^{-\mathbf{2}}\right]$ & $\mathbf{E}_{\text {disl }}[\mathbf{J} / \mathbf{g}]$ & $\mathbf{E}_{\mathbf{v a c}}[\mathbf{J} / \mathbf{g}]$ & $\mathbf{c}_{\mathbf{v}}\left[\mathbf{1 0}^{-\mathbf{6}}\right]$ \\
\hline Mg5Zn & $0.6 \pm 0.08$ & $3.8 \pm 0.1$ & $0.5 \pm 0.06$ & $0.07 \pm 0.01$ & $20 \pm 6.0$ \\
Mg5Zn0.3Ca & $0.4 \pm 0.08$ & $3.3 \pm 0.1$ & $0.4 \pm 0.04$ & $0.02 \pm 0.01$ & $6 \pm 1.0$ \\
Mg5Zn0.15Ca & $0.4 \pm 0.1$ & $3.5 \pm 0.1$ & $0.4 \pm 0.1$ & $0.01 \pm 0.001$ & $3 \pm 1.0$ \\
Mg5Zn0.15Ca0.15Zr & $0.4 \pm 0.1$ & $4.5 \pm 0.1$ & $0.4 \pm 0.06$ & $0.01 \pm 0.001$ & $0.6 \pm 0.1$ \\
\hline
\end{tabular}

Similar to our paper [15] DSC also provided the defect migration enthalpies Q (Figure 10) being characteristic of the type of the annealing defect, by means of the KissingerOzawa method [30]. The results for activation enthalpies of peak I and peak II were between 0.6-1.5 $\pm 0.1 \mathrm{eV}$, and between 1.3-3.4 $\pm 0.3 \mathrm{eV}$, respectively, for all alloys Mg5Zn0.3Ca, Mg5Zn, Mg5Zn0.15Ca and Mg5Zn0.15Ca0.15Zr.

\subsection{Corrosion Tests}

Results of the immersion tests of Mg5Zn in simulated body fluid at human body temperature are shown in Figure 11. The corrosion rate is presented as a function of immersion time. It can be seen that the corrosion rate is highest directly after the start of the test. After each renewal of the SBF peak-link increase in the corrosion rate was observed. Although the results have an apparent scatter, it can be seen that except for in the first days, HPT processing at $285^{\circ} \mathrm{C}$ leads to a clearly lower corrosion rate compared to the as-cast condition. The subsequent heat treatment at $100{ }^{\circ} \mathrm{C}$ does not significantly change the corrosion rate. When analyzing the results for the samples heat treated at $150{ }^{\circ} \mathrm{C}$ after HPT processing; however, a slight tendency to higher corrosion rates could be observed, especially during the second week of testing. 


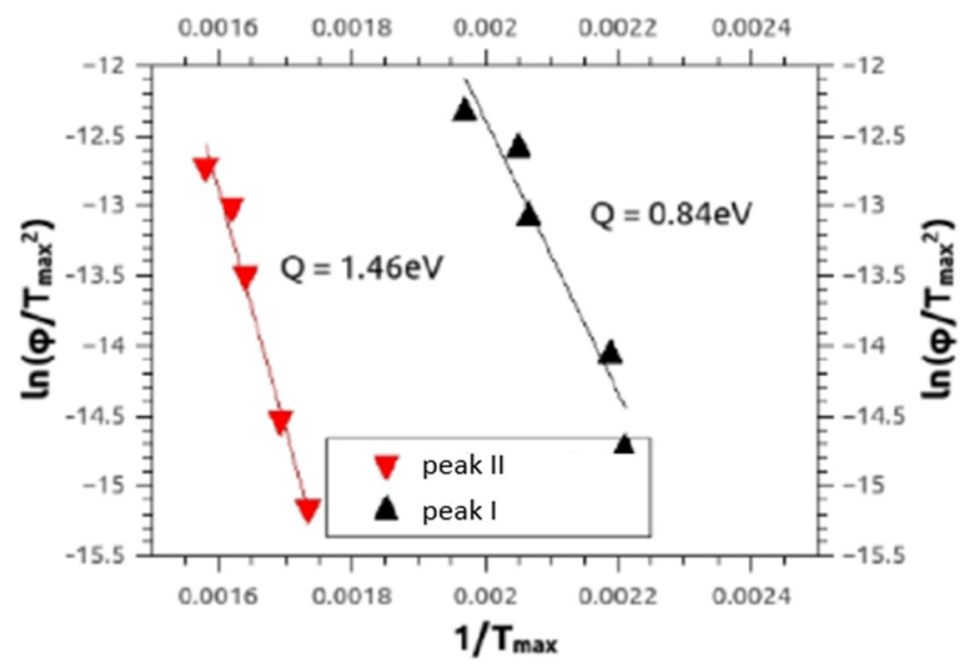

Figure 10. Typical Kissinger plots referring to Equation (5) for peak I and peak II measured by DSC, for HPT-processed $\mathrm{Mg} 5 \mathrm{Zn}$ at $4 \mathrm{GPa}$ for $10 \mathrm{rot}$. at $285^{\circ} \mathrm{C}$. The full lines represent the regressions to the experimental data, from which the activation enthalpies $\mathrm{Q}$ given were calculated.

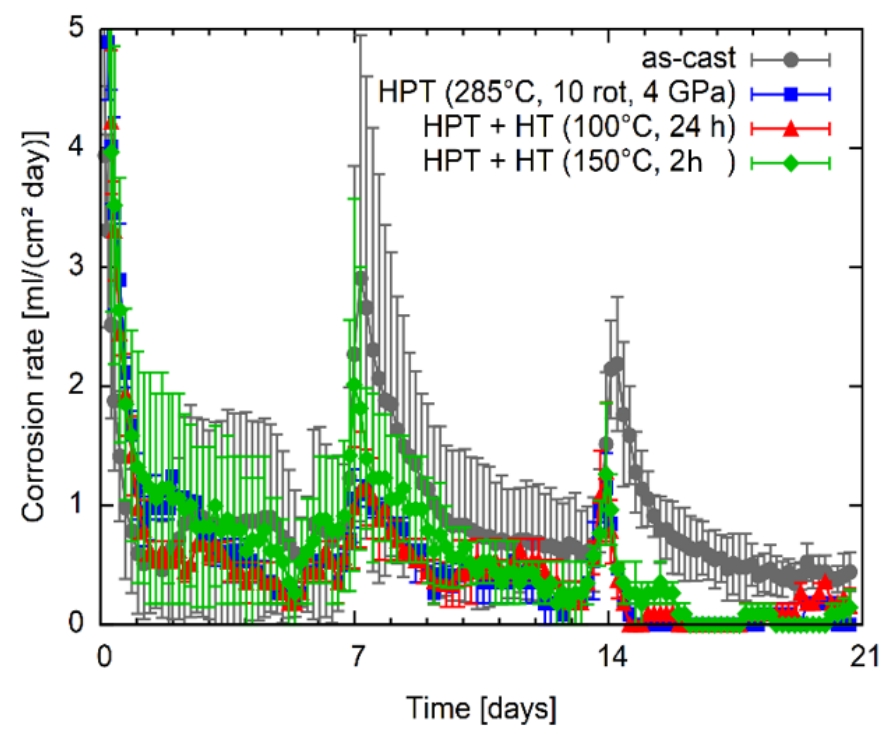

Figure 11. Corrosion rate of the Mg5Zn alloy in as-cast, HPT-deformed as well as subsequently heat-treated conditions as a function of the immersion time.

\section{Discussion}

\subsection{The Effects of Warm HPT Processing and Additional Heat Treatments}

Learning from the deficiencies of materials studied in our previous work [15], two goals were followed in the present one, i.e., to (i) entirely re-solutionize the primary precipitates which remained from casting, to (ii) increase the ductility without compromising high strength values, and to (iii) leave other beneficial properties such as low Young's modulus and corrosion rate unaffected. We tried to reach these goals by increasing the HPT processing temperature to $285^{\circ} \mathrm{C}$ of all four alloys, applying $4 \mathrm{GPa}$ and 10 rotations (i.e., $\varepsilon_{\mathrm{vM}}=330$ ). The temperature $285{ }^{\circ} \mathrm{C}$ was chosen in order not to exceed the Scheil solidus $\left(294^{\circ} \mathrm{C}\right)$ thus avoiding incipient melting [34,35]. As in [15], additional isothermal treatments at $\mathrm{T}=100{ }^{\circ} \mathrm{C}$ and $150{ }^{\circ} \mathrm{C}$ were carried out to further approach the goals (i) and (ii).

Concerning goal (i), indeed the primary precipitates could be eliminated in all alloys except Mg5Zn0.3Ca where at least their volume fraction remained below 1\% (Figure 3). 
As for goal (ii), increases of microhardness of up to $55 \%$ were achieved by the warm HPT-processing, not at least thanks to the very high strains being 2.5 times larger compared to those of low-temperature HPT-processing in [15]. Furthermore, additional strength increases of $25 \%$ and $20 \%$ occurred due to the subsequent isothermal heat treatment after $\mathrm{HPT}$, at $\mathrm{T}=100{ }^{\circ} \mathrm{C}$ and $150{ }^{\circ} \mathrm{C}$, respectively, followed by a decrease after $24 \mathrm{~h}$ and $2 \mathrm{~h}$, respectively, reflecting a kind of over-aging process. All the strength increases are not only seen in microhardness but also in tensile tests either in yield stress or ultimate tensile strength. Above all, the latter show the significant increase of ductility of the current warm HPT processing and/or thermal treatments compared to the low-temperature HPT processing/thermal treatments reported in the papers [8,15] Figure 6 and Table 4, being now at least $16-19 \%$ instead of about $5 \%$ previously.

Also goal (iii) could be reached with the warm HPT processing and thermal treatments: nor did the rather low initial Young's modulus of about $40 \mathrm{GPa}$ of all the Mg alloys investigated change after warm HPT processing or after additional heat treatment. The same is true for the corrosion rate except the materials heat treated at $150{ }^{\circ} \mathrm{C}$ after $\mathrm{HPT}$ processing, where some tendency of increase was observed.

\subsection{Reasons for the Effects of Warm HPT-Processing and Additional Heat Treatments}

First, we wish to clarify where the observed increases in strength (both microhardness and yield stress/UTS) come from. During warm HPT processing, the grain size decreased by about a factor of 2 within the range 10-100 $\mu \mathrm{m}$. In fact, the average grain size decreased from $49 \mu \mathrm{m}$ to $25 \mu \mathrm{m}$ which causes-according to a recent review on Hall-Petch relationships in Mg alloys ([36], see Figure 6 therein) — an increase of about 7\% of the flow stress, which is only $10 \%$ of the total HPT-induced flow stress (compare Figure 6 of this work); the additional heat treatments showed no detectable change in grain size at all, so that -in a search of the main sources of strength increases-we focused on other reasons. These are: (i) HPT-generated dislocations, (ii) HPT-induced formation of precipitations, and/or (iii) hardening from HPT-generated vacancy agglomerates, as has been shown for Mg alloys by Horky et al. [8] and Ojdanic et al. [15].

Discussing first the effects of warm HPT-processing, the formation of precipitates (ii) can be ruled out as the TEM observations showed no differences-either in the type or density - of precipitation microstructure. Precipitates can only contribute to macroscopic strength being already present before HPT-processing treatment; according to our investigations reported in papers $[9,15]$ its contribution may amount $20 \%$ at maximum. However, considering the dislocation densities produced by HPT-processing at low and high temperatures, both amounted to about $\rho \cong 6.3 \times 10^{14} \mathrm{~m}^{2}$, not least due to the large deformation applied in case of high temperature deformation, balancing the generally lower dislocation densities produced at the higher deformation temperature. Assuming the interaction/configuration parameter of dislocations $\alpha=0.1$ in highly deformed microstructures, as part of the Taylor equation:

$$
\Delta H=m \sigma=m M \Delta \tau=m M \alpha G b \sqrt{\rho}
$$

with $M=4.2$ as the Taylor factor, $m=4.2$ Tabor's factor, $\mathrm{G}$ and $\mathrm{b}$ as shear modulus and Burgers vector, respectively (values see Equation (2)), a value of $\Delta H=294 \mathrm{MPa}$ results which just fits to the missing $80 \%$ of the measured total increase of strength due to work hardening. Because of the higher deformation temperature in warm HPT processing, however, $\alpha=0.08$ may be more realistic because of a more recrystallized microstructure compared to that of low-temperature HPT [15], with less internal stresses and the extended ductility observed. Using (5) with $\alpha=0.08$, the dislocation-caused strength becomes smaller and, with regard to the contribution of grain refinement being about $7 \%$ (see estimation in first paragraph of this section), the precipitation part is responsible for at least $20 \%$ of the total strength.

Now let us consider reasons for the further hardening observed during additional heat treatment at $100{ }^{\circ} \mathrm{C}$ and $150{ }^{\circ} \mathrm{C}$. The reason (ii) was that precipitation hardening is 
not relevant as neither additional nor a new type of precipitate could be observed by TEM after $100^{\circ} \mathrm{C}$ aging; on the other hand, the new type of precipitates observed by TEM at $150{ }^{\circ} \mathrm{C}$ aging seems to be not important because no hardening but softening effects were found at this aging temperature. Considering reason (i) dislocation hardening, this can be ruled out as the dislocation density did not increase during additional heat treatment, and rearrangements of dislocations can only lead to softening rather than hardening. Therefore, as argued in our previous works [8,15], it is only the agglomeration of vacancies that can lead to hardening during the heat treatment. An estimation can be done by means of Kirchner's model [37]:

$$
\Delta \sigma=\frac{G b}{k} N^{a} d^{3 a-1}
$$

Here, $N$ means the loop density (number of loops $/ \mathrm{m}^{3}$ ), $\mathrm{d}$ the average loop diameter, and $a$ and $k$ constants which depend on the ratio of loop distance $\left(\lambda=N^{-1 / 3}\right)$ to diameter. For a ratio $\lambda / d>10$, the constants are equal to $a=1 / 2$ and $k=0.122$, otherwise $a=4 / 3$ and $k=0.001$. Equation (6) shows that the strengthening of loops becomes stronger when the loop density is larger.

The amount of loop hardening in Kirchner's equation can be estimated by inserting the determined values for the vacancy concentration from Table 5, and by an assumption for the loop diameter $d$ (10-100 nm [38]). For the loops' Burgers vector, $b=0.32 \mathrm{~nm}$ was taken. The number of vacancies per loop ( $\operatorname{vac}_{\text {loop}}$ ), and the loop density $N$ assuming circular loops are given by:

$$
\begin{gathered}
v_{\text {ac }} \text { loop } \\
N=\frac{d^{2} \pi}{4 b^{2}} \\
v=\frac{c_{V}}{v a c_{\text {loop }}}
\end{gathered}
$$

where $c_{v}$ is the vacancy concentration assuming that all of them form loops. The calculated dependence of theoretical yield strength on average vacancy concentration for different loop sizes is shown in Figure 12. For the alloy Mg5Zn0.3Ca studied in this work, it can be seen that according to the model, a vacancy concentration of the order $c_{v} \cong 10^{-6}$ is already sufficient to account for the observed hardening of $\Delta \sigma=14-34 \mathrm{MPa}$, with loop sizes being between 15-50 $\mathrm{nm}$.

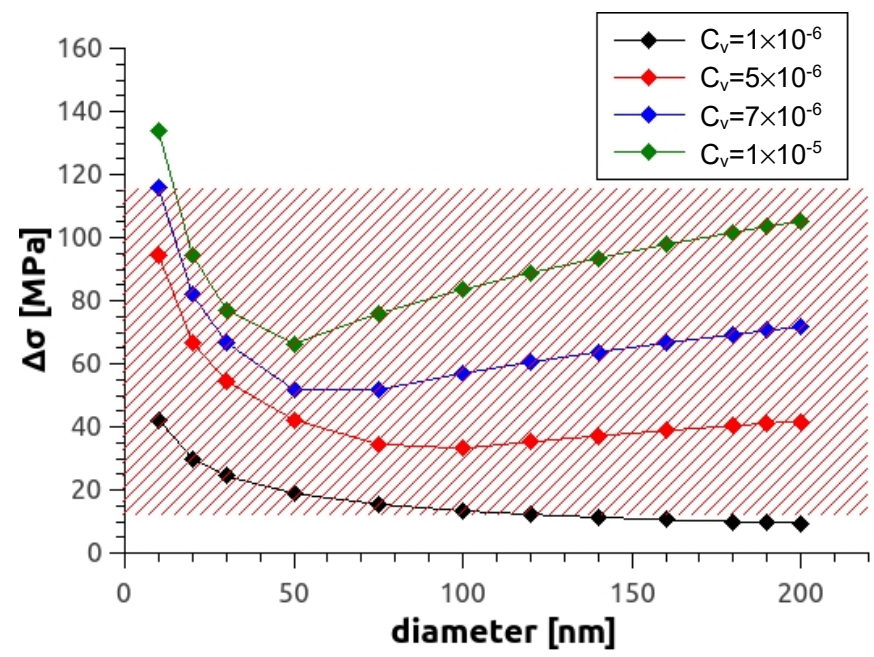

Figure 12. Increase of strength as a function of loop diameter at various vacancy concentrations. The red shaded area represents values of possible vacancy-induced strength in investigations $[8,15]$ and the current one.

For the alloys investigated in this paper, the measured generated vacancy concentrations amount to typically $c_{v} \cong 10^{-4}$, and one wonders why the vacancy hardening is not much larger than observed. The answer is two-fold: (i) at the aging temperatures 
100-150 ${ }^{\circ} \mathrm{C}$, according to the DSC plot, vacancies not only agglomerate but also start to anneal, and (ii) not all vacancies that resist annealing are part of agglomerates and stay single, as already reported from similar simulations in the previous study [15].

The fact that the hardness peak at $100{ }^{\circ} \mathrm{C}$ after $24 \mathrm{~h}$ of heat treatment is caused by vacancy agglomeration [18] is confirmed by the DSC measurements, which show peak I (Figure 9) to start already at this very temperature. The number of dislocations that also anneal at this temperature, however, is about $25 \%$ higher than in the case of lowtemperature HPT-processing described in our paper [15]; this indicates that already at this temperature some primary recrystallization has taken place, which is in accordance with the special features of textures of warm-HPT presented in Section 3.4 of this paper. It is also well known that microstructures during and/or after recrystallization are poor in internal stresses compared to those immediately after plastic deformation; this explains why the ductility of warm HPT-processed materials is much larger (3x, until about $15 \%)$ than in the case of low-temperature HPT-processed ones (for the consequences to the dislocation configuration parameter $\alpha$, see above).

The present Kissinger analyses are in line with the above interpretation of annealing processes. Concerning peak I, they show-all materials included-activation enthalpies $\mathrm{Q}(\mathrm{I})$ between $0.6-1.5 \mathrm{eV}$, which agrees with literature values of vacancy migration enthalpy for $\mathrm{Mg}$ and $\mathrm{Mg}$ alloys, being 0.8-1.0 eV [29]. The evaluated Q(I) values, however, extend to $1.5 \mathrm{eV}$, which indicates that dislocations may start to anneal already within peak I. The enthalpies Q(II) evaluated for peak II are-in any case-in accordance with those of dislocation annealing/primary recrystallization as they equal to values between 1.3 and $3.4 \mathrm{eV}$. The average error for both values is $\pm 0.3 \mathrm{eV}$.

When comparing the stress-strain curves of the alloys after HPT-processing at 10 rotations at $285^{\circ} \mathrm{C}$ and those additionally heat treated at $100{ }^{\circ} \mathrm{C}$ for $24 \mathrm{~h}$ (Figure 6), it can be seen that ductility is not affected by the thermal treatments. Compared to the processing method of the previous study, it is obvious that already the samples' HPT processed at $285^{\circ} \mathrm{C}$ by 10 rotations are much more ductile than samples HPT processed at RT by 0.5 rotations. The brittleness of the latter samples may be caused by the formation of a large number of vacancy agglomerates along with immobile dislocations. Anyway, in the current study, the vacancy concentration and therefore the concentration of vacancy agglomerates is much lower (about one order of magnitude [15]).

As concerns the effects of warm HPT processing and/or thermal treatment on the Young's modulus, for all materials, the microindentation measurements of Young's modulus E showed moderate differences of E by 11 GPa between the HPT-processed and additionally heat treated conditions, and by only $4 \mathrm{GPa}$ at maximum within the same material (Table 4). Compared to the E-values after low- temperature HPT, and after HPT plus heat treatment [15], the E-values in this work are generally lower, which may be attributed to texture features typical of dynamic recrystallization (higher processing temperature) and static recrystallization (annealing treatment), compare Figure 7 [32,33]. In general, E stays low for all alloys i.e., it does not exceed $42 \mathrm{GPa}$ which is still close to that of bone $(\mathrm{E}=10-30 \mathrm{GPa})$ [39]; thus the conditions to avoid the stress-shielding effect in implant applications [2] are still fulfilled.

\subsection{Corrosion Behavior during Processing}

It is known that precipitates can strongly influence the corrosion behavior of $\mathrm{Mg}$ alloys [40]. Most precipitates are more noble than the $\mathrm{Mg}$ matrix and, therefore, increase the dissolution of the material; however, depending on their number and distribution in the material also other effects can occur [41,42]. In the case of Mg5Zn alloy under investigation in this work, the dissolution of primary precipitates by the warm HPT-processing was achieved, which results in the decrease of corrosion rate as shown in Figure 11. The high number of dislocations generated during the warm HPT-processing does not seem to affect the corrosion rate. Subsequent heat treatments applied on the HPT-processed material increase the hardness and strength by the generation of vacancy agglomerates, not by 
the formation of precipitates. As the corrosion rate shows no significant change, it seems that the agglomeration of deformation induced vacancies-like the dislocations-do not increase the corrosion rate.

\section{Summary and Conclusions}

In the present study, new routes for the improvement of various $\mathrm{MgZnCa}(\mathrm{Zr})$ alloys with respect to their mechanical and corrosion properties were investigated. Two ternary alloys (Mg5Zn0.3Ca and Mg5Zn0.15Ca), one quaternary (Mg5Zn0.15Ca0.15Zr) and one binary alloy $(\mathrm{Mg} 5 \mathrm{Zn})$ were studied via measurements of hardness, Young's modulus, tensile strength and of the corrosion rates; in parallel numerous microstructural investigations were undertaken by applying methods of optical and electron microscopy, and especially of X-ray diffraction and DSC to analyze the nature and density of lattice defects involved. The alloys were processed by warm HPT for 10 rotations (von Mises equivalent strain $\left.\varepsilon_{\mathrm{vM}}=330\right)$ at $285^{\circ} \mathrm{C}$ as well as by additional heat treatments at $60-150{ }^{\circ} \mathrm{C}$ in a silicon oil bath.

The use of warm HPT plus subsequent thermal treatment as a processing tool is beneficial with respect to several features:

(i) re-solutionizing of primary precipitates being possible sources of corrosion and brittleness;

(ii) generation a high number of dislocations; those account for the major part i.e., for more than $70 \%$ of the whole HPT-induced increase of strength (being $55 \%$ ); $7 \%$ of it can be ascribed to the decrease of grain size. The considerable ductility $(15 \%)$ can be related to the low level of internal stresses, thanks to near-equilibrium arrangements of dislocations achieved by the high HPT-processing temperature.

(iii) extra hardening (at least 20\%) coming from thermal treatment allowing for the agglomeration of deformation induced vacancies;

(iv) precipitates that contribute also more than $20 \%$ to the total strength are present after HPT at the latest; however, they do not change during thermal treatment and thus do not contribute to the related hardening, nor decrease ductility;

(v) although there have been indications of dynamic and static recrystallization in the materials' textures, they did not significantly affect the values of Young's modulus, nor the experimental or the calculated values;

(vi) thanks to the elimination of primary precipitates, the corrosion rates could be decreased by the current processing route. Neither the generation of dislocations nor that of vacancy agglomerates had a marked impact on corrosion rates.

These features suggest the materials and especially the described processing route to be very appropriate for biodegradable implant materials.

Author Contributions: Conceptualization, M.J.Z. and D.O.; formal analysis, A.M.-O.; investigation, A.M.-O., J.H., M.F., B.S.; data curation, A.M.-O., J.H., M.J.Z., E.S., D.O., M.F. and B.S.; writingoriginal draft preparation, A.M.-O.; writing—review and editing, M.J.Z., D.O., J.H., B.S., B.M. and M.F.; supervision, E.S., M.J.Z., D.O. and S.G.; project administration, D.O., M.J.Z., M.V. and S.G.; funding acquisition, D.O., M.J.Z., M.V. and S.G. All authors have read and agreed the published version of the manuscript.

Funding: This research was funded by the Slovenian Research Agency ARRS, J2-7157 and program P2-0412; Austrian Science Fund FWF, research project I2815-N36; Austrian and Polish Exchange Services, projects PL 14/2017 and PL 14/2019. The APC was funded by the Austrian Science Fund FWF.

Data Availability Statement: Source data necessary to reproduce the results reported in this paper cannot be shared at the time of publication since they also form a part of an ongoing study. However, they can be made available upon request.

Acknowledgments: The authors gratefully acknowledge financial support from projects J2-7157 and research program P2-0412 of the Slovenian Research Agency ARRS. Funding is also appreciated from project I2815-N36 granted by Austrian Science Fund FWF. B.S., A.O. and M.J.Z. are grateful to the 
Austrian and Polish Exchange Services for financing several mutual visits within projects PL 14/2017 and PL 14/2019.

Conflicts of Interest: The authors declare no conflict of interest.

\section{References}

1. Reith, G.; Schmitz-Greven, V.; Hensel, K.O.; Schneider, M.M.; Tinschmann, T.; Bouillon, B.; Probst, C. Metal implant removal: Benefits and drawbacks-A patient survey. BMC Surg. 2015, 15, 96. [CrossRef]

2. Ridzwan, M.I.Z.; Shuib, S.; Hassan, A.Y.; Shokri, A.A.; Mohamad Ibrahim, N.M. Problem of Stress Shielding and Improvement to the Hip Implant Designs: A Review. J. Med. Sci. 2007, 7, 460-467. [CrossRef]

3. Chen, Y.-J.; Wang, Q.-D.; Lin, J.-B.; Liu, M.-P.; Hjelen, J.; Roven, H.J. Grain refinement of magnesium alloys processed by severe plastic deformation. Trans. Nonferr. Met. Soc. China 2014, 24, 3747-3754. [CrossRef]

4. Witte, F. The history of biodegradable magnesium implants: A review. Acta Biomater. 2010, 6, 1680-1692. [CrossRef] [PubMed]

5. Qi, F.; Zhang, D.; Zhang, X.; Xu, X. Effect of Sn addition on the microstructure and mechanical properties of Mg-6Zn-1Mn (wt.\%) alloy. J. Alloys Compd. 2014, 585, 656-666. [CrossRef]

6. Liu, Y.-C.; Liu, D.-B.; Zhao, Y.; Chen, M.-F. Corrosion degradation behavior of Mg-Ca alloy with high Ca content in SBF. Trans. Nonferr. Met. Soc. China 2015, 25, 3339-3347. [CrossRef]

7. Witte, F.; Hort, N.; Vogt, C.; Cohen, S.; Kainer, K.U.; Willumeit, R.; Feyerabend, F. Degradable biomaterials based on magnesium corrosion. Curr. Op. Sol. Stat. Mater. Sci. 2008, 12, 63-72. [CrossRef]

8. Horky, J.; Ghaffar, A.; Werbach, K.; Mingler, B.; Pogatscher, S.; Schäublin, R.; Setman, D.; Uggowitzer, P.J.; Löffler, J.F.; Zehetbauer, M.J. Exceptional Strengthening of Biodegradable Mg-Zn-Ca Alloys through High Pressure Torsion and Subsequent Heat Treatment. Materials 2019, 12, 2460. [CrossRef] [PubMed]

9. Ojdanic, A.; Schafler, E.; Horky, J.; Orlov, D.; Zehetbauer, M. Strengthening of a Biodegradable Mg-Zn-Ca Alloy ZX50 After Processing by HPT and Heat Treatment. In Magnesium Technology 2018; Orlov, D., Joshi, V., Solanki, K., Eds.; Springer International Publishing: Cham, Switzerland, 2018; pp. 277-282. ISBN 978-3-319-72332-7.

10. Mohamed, A.; El-Aziz, A.M.; Breitinger, H.-G. Study of the degradation behavior and the biocompatibility of Mg-0.8Ca alloy for orthopedic implant applications. J. Magn. Alloys 2019, 7, 249-257. [CrossRef]

11. Stefanidou, M.; Maravelias, C.; Dona, A.; Spiliopoulou, C. Zinc: A multipurpose trace element. Arch. Toxicol. 2006, 80, 1-9. [CrossRef]

12. Schroeder, H.A.; Balassa, J.J. Abnormal trace metals in man: Zirconium. J. Chronic Dis. 1966, 19, 573-586. [CrossRef]

13. Hänzi, A.C.; Dalla Torre, F.H.; Sologubenko, A.S.; Gunde, P.; Schmid-Fetzer, R.; Kuehlein, M.; Löffler, J.F.; Uggowitzer, P.J. Design strategy for microalloyed ultra-ductile magnesium alloys. Phil. Mag. Lett. 2009, 89, 377-390. [CrossRef]

14. Hänzi, A.C.; Sologubenko, A.S.; Gunde, P.; Schinhammer, M.; Uggowitzer, P.J. Design considerations for achieving simultaneously high-strength and highly ductile magnesium alloys. Phil. Mag. Lett. 2012, 92, 417-427. [CrossRef]

15. Ojdanic, A.; Horky, J.; Mingler, B.; Fanetti, M.; Gardonio, S.; Valant, M.; Sulkowski, B.; Schafler, E.; Orlov, D.; Zehetbauer, M.J. The Effects of Severe Plastic Deformation and/or Thermal Treatment on the Mechanical Properties of Biodegradable Mg-Alloys. Metals 2020, 10, 1064. [CrossRef]

16. Pippan, R.; Scheriau, S.; Hohenwarter, A.; Hafok, M. Advantages and limitations of HPT: A Review. Mater. Sci. Forum 2008, 584, 16-21. [CrossRef]

17. Korznikova, E.; Schafler, E.; Steiner, G.; Zehetbauer, M.J. Measurements of vacancy type defects in SPD deformed Ni. In Proceedings of the Proc. 4th International Symposium on Ultrafine Grained Materials, Antonio, TX, USA, 12-16 March 2006; Zhu, Y.T., Langdon, T.G., Horita, Z., Zehetbauer, M.J., Semiatin, S.L., Lowe, T.C., Eds.; The Minerals, Metals \& Materials Society (TMS): Warrendale, PA, USA, 2006; pp. 97-104.

18. Setman, D.; Schafler, E.; Korznikova, E.; Zehetbauer, M.J. The presence and nature of vacancy type defects in nanometals detained by severe plastic deformation. Mater. Sci. Eng. A 2008, 493, 116-122. [CrossRef]

19. Schafler, E.; Steiner, G.; Korznikova, E.; Kerber, M.; Zehetbauer, M.J. Lattice defect investigation of ECAP-Cu by means of X-ray line profile analysis, calorimetry and electrical resistometry. Mater. Sci. Eng. A 2005, 410-411, 169-173. [CrossRef]

20. Cengeri, P.; Kerber, M.B.; Schafler, E.; Zehetbauer, M.J.; Setman, D. Strengthening during heat treatment of HPT processed copper and nickel. Mater. Sci. Eng. A 2019, 742, 124-131. [CrossRef]

21. Zehetbauer, M. Effects of Non-Equilibrium Vacancies on Strengthening. Key Eng. Mater. 1995, 97-98, 287-306. [CrossRef]

22. Orlov, D.; Pelliccia, D.; Fang, X.; Bourgeois, L.; Kirby, N.; Nikulin, A.Y.; Ameyama, K.; Estrin, Y. Particle evolution in Mg-Zn-Zr alloy processed by integrated extrusion and equal channel angular pressing: Evaluation by electron microscopy and synchrotron small-angle X-ray scattering. Acta Mater. 2014, 72, 110-124. [CrossRef]

23. Mima, G.; Tanaka, Y. The aging characteristics of magnesium-4wt\% zinc alloy. Trans. JIM 1971, 12, 71-75. [CrossRef]

24. Mima, G.; Tanaka, Y. The main factors affecting the aging of magnesium-zinc alloys. Trans. JIM 1971, 12, 76-81. [CrossRef]

25. Clark, J.B. Transmission electron microscopy study of age hardening in a Mg-5 wt.\% Zn alloy. Acta Metall. 1965, 13, 1281-1289. [CrossRef]

26. Ungár, T.; Tichy, G.; Gubicza, J.; Hellmig, R.J. Correlation between subgrains and coherently scattering domains. Powder Diffr. 2005, 20, 366-375. [CrossRef] 
27. Schafler, E.; Zehetbauer, M. Characterization of nanostructured materials by X-ray line profile analysis. Rev. Adv. Mater. Sci 2005, 10, 28-33. [CrossRef]

28. Bever, M.B.; Holt, D.L.; Titchener, A.L. The Stored Energy of Cold Work. Progr. Mater. Sci. 1973, 17, 5-177. [CrossRef]

29. Tzanetakis, P.; Hillairet, J.; Revel, G. The Formation Energy of Vacancies in Aluminium and Magnesium. Phys. Stat. Sol. 1976, 75, 433-439. [CrossRef]

30. Kissinger, H.E. Reaction kinetics in differential thermal analysis. Anal. Chem. 1957, 29, 1702-1706. [CrossRef]

31. Müller, L.; Müller, F.A. Preparation of SBF with different HCO3- content and its influence on the composition of biomimetic apatites. Acta Biomater. 2006, 2, 181-189. [CrossRef] [PubMed]

32. Bonarski, B.J.; Schafler, E.; Mingler, B.; Skrotzki, W.; Mikulowski, B.; Zehetbauer, M.J. Texture evolution of Mg during highpressure torsion. J. Mater. Sci. 2008, 43, 7513-7518. [CrossRef]

33. Beausir, B.; Biswas, S.; Kim, D.I.; Toth, L.S.; Suwas, S. Analysis of microstructure and texture evolution in pure magnesium during symmetric and asymmetric rolling. Acta Mater. 2009, 57, 5061-5077. [CrossRef]

34. Sundman, B.O.; Ansara, I. III.2-The Gulliver-Scheil method for the calculation of solidification paths. In The SGTE Casebook: Thermodynamics at Work, 2nd ed.; Hack, K., Ed.; Woodhead Pub: Cambridge, UK; Boca Raton, FL, USA, 2008; pp. 343-346, ISBN 978-1-84569-215-5.

35. Gulliver, G.H. The quantitative effect of rapid cooling upon the constitution of binary alloys. J. Inst. Met. 1913, 9, $120-157$.

36. Yu, H.; Xin, Y.; Wang, M.; Liu, Q. Hall-Petch relationship in Mg alloys: A review. J. Mater. Sci. Technol. 2018, 34, 248-256. [CrossRef]

37. Kirchner, H.O.K. Loop hardening of hexagonal metals. Z. Metallk. 1976, 67, 525-532.

38. Hampshire, J.M.; Hardie, D. Hardening of pure magnesium by lattice defects. Acta Metall. 1974, 22, 657-663. [CrossRef]

39. Radha, R.; Sreekanth, D. Insight of magnesium alloys and composites for orthopedic implant applications-A review. J. Magn. Alloys 2017, 5, 286-312. [CrossRef]

40. Song, G.-L. Corrosion electrochemistry of magnesium (Mg) and its alloys. In Corrosion of Magnesium Alloys; Song, G.-L., Ed.; Woodhead Pub: Oxford, UK; Philadelphia, PA, USA, 2011; pp. 3-65. ISBN 9781845697082.

41. Mostaed, E.; Hashempour, M.; Fabrizi, A.; Dellasega, D.; Bestetti, M.; Bonollo, F.; Vedani, M. Microstructure, texture evolution, mechanical properties and corrosion behavior of ECAP processed ZK60 magnesium alloy for biodegradable applications. J. Mech. Behav. Biomed. Mater. 2014, 37, 307-322. [CrossRef] [PubMed]

42. Orlov, D.; Ralston, K.D.; Birbilis, N.; Estrin, Y. Enhanced corrosion resistance of Mg alloy ZK60 after processing by integrated extrusion and equal channel angular pressing. Acta Mater. 2011, 59, 6176-6186. [CrossRef] 